Cahiers $d u$ MONDE RUSSE

\section{Cahiers du monde russe}

Russie - Empire russe - Union soviétique et États indépendants

45/3-4 | 2004

Varia

\title{
Aleš Erjavec, ed., Postmodernism and the postsocialist condition
}

\section{Michel Aucouturier}

\section{OpenEdition \\ Journals}

Édition électronique

URL : https://journals.openedition.org/monderusse/4214

DOI : $10.4000 /$ monderusse.4214

ISSN : $1777-5388$

Éditeur

Éditions de l'EHESS

\section{Édition imprimée}

Date de publication : 1 juillet 2004

Pagination : 732

ISBN : 2-7132-2009-2

ISSN : $1252-6576$

Référence électronique

Michel Aucouturier, «Aleš Erjavec, ed., Postmodernism and the postsocialist condition », Cahiers du monde russe [En ligne], 45/3-4 | 2004, mis en ligne le 03 juin 2009, consulté le 03 septembre 2022. URL : http://journals.openedition.org/monderusse/4214; DOI : https://doi.org/10.4000/monderusse. 4214

Ce document a été généré automatiquement le 3 septembre 2022.

Tous droits réservés 


\title{
Aleš Erjavec, ed., Postmodernism and the postsocialist condition
}

\author{
Michel Aucouturier
}

\section{RÉFÉRENCE}

Aleš ERJAVEC, ed., Postmodernism and the postsocialist condition. Politicized art under late socialism. Berkeley-Los Angeles-Londres, University of California Press, 2003, $297 \mathrm{p}$.

1 Le philosophe slovène Aleš Erjavec, président de l'Association internationale d'esthétique, a réuni dans ce livre six études d'esthéticiens et critiques d'art "locaux " (dont lui-même) consacrées à l'art des années 1970-1990 dans six pays ou aires géographiques ayant appartenu ou appartenant encore au monde socialiste.

Boris Groys (« The other gaze: Russian unofficial art's view of the Soviet world ») retrace brièvement l'histoire de l'art « dissident » en URSS, et s'arrête plus longuement sur les représentants de ces variantes du post-modernisme que sont le « conceptualisme » (Il'ja Kabakov) et surtout le «soc'art» (Komar et Melamid). Miško Šuvakovi (« Art as a political machine: fragments on the late socialist and postsocialist art of Mitteleuropa and the Balkans ») illustre son propos par la présentation des œuvres des Tchèques Milan Knížák et Milan Kunc, des Serbes Rasa Todosijevi et Goran Djordjevi, du Hongrois Balint Szombathy, du Croate Mladen Stilinovi, du groupe roumain subREAL. Aleš Erjavec (« Neue slowenische Kunst - New Slovenian art: Slovenia, Yugoslavia, self-management, and the 1980s ») s'attarde sur le cas particulier de la Slovénie, et cherche dans l'évolution spécifique du socialisme yougoslave l'explication des positions « révolutionnaires » du groupe musical, puis artistique, Laibach. Péter György (« Hungarian Marginal Art in the Late Period of State Socialism ») fait apparaître les traits originaux du post-modernisme hongrois chez des artistes marqués par l'architecture utopique des constructivistes (Gábor Bachman, László Rajk, Attila Kovács, Tibor Szalai). 
3 Enfin, Gerardo Mosquera (« The new Cuban art ») et Gao Minglu (« Post-utopian avantgarde art in China ») présentent la situation particulière de deux pays extra-européens n'ayant pas rejeté à ce jour le système socialiste.

4 L'objet de cette confrontation, exposé par Aleš Erjavec dans une longue étude introductive, est de faire apparaitre, par-delà les différences dues aux traditions artistiques propres à chacun de ces pays (et particulièrement sensibles dans le cas de Cuba et de la Chine), les traits communs qui résultent de leur appartenance commune (pour l'époque considérée) au système socialiste (saisi ici dans la phase de son déclin), marqué par la subordination de l'art à l'idéologie du parti et la conservation de l'esthétique traditionnelle de la représentation sous l'étiquette du « réalisme socialiste ».

5 L'apparition de formes d'art non-conformistes, étrangères à ce " canon » et renouant avec les tendances « modernistes » de l'art contemporain, est l'une des manifestations de ce déclin, en particulier dans l'URSS des années 1960-1970. Mais elle ne touche qu'une élite et n'a qu'une faible incidence politique. Au contraire, les courants postmodernistes, marqués par la réutilisation ironique du langage de la culture de masse, imprégnée ici par la symbolique communiste, ont une portée subversive qui les distingue globalement des courants analogues de l'art occidental.

6 Une illustration abondante et de grande qualité permet de suivre et de mieux comprendre ce chapitre tout récent de l'histoire de l'art contemporain. 